\title{
Curative resection of pancreatic ductal adenocarcinoma developing in the remnant pancreas 13 years after distal pancreatectomy for intraductal papillary mucinous neoplasms: A case report
}

\author{
TAKAHIRO EINAMA ${ }^{1}$, HIROFUMI KAMACHI ${ }^{1}$, TOSHIHIRO SAKATA ${ }^{1}$, KENGO SHIBATA $^{1}$, \\ KAZUKI WAKIZAKA ${ }^{1}$, KO SUGIYAMA ${ }^{1}$, KAZUAKI SHIBUYA ${ }^{1}$, SHINGO SHIMADA ${ }^{1}$, \\ KENJI WAKAYAMA $^{1}$, TATSUYA ORIMO ${ }^{1}$, HIDEKI YOKOO ${ }^{1}$, TOSHIYA KAMIYAMA ${ }^{1}$, \\ TOMOKO MITSUHASHI ${ }^{2}$ and AKINOBU TAKETOMI ${ }^{1}$ \\ ${ }^{1}$ Department of Gastroenterological Surgery I, Hokkaido University Graduate School of Medicine; \\ ${ }^{2}$ Department of Surgical Pathology, Hokkaido University Hospital, Sapporo, Hokkaido 060-8638, Japan
}

Received July 13, 2017; Accepted November 22, 2017

DOI: $10.3892 /$ mco.2018.1556

\begin{abstract}
Intraductal papillary mucinous neoplasms (IPMNs) are characterized by the papillary proliferation of atypical mucinous epithelial cells in the pancreatic ductal system. There are two recurrence patterns following resection of IPMNs: Metachronous multifocal occurrence of IPMNs, and distinct pancreatic ductal adenocarcinoma (PDAC) in the remnant pancreas. Several recent studies investigated the development of distinct PDAC during follow-up evaluation of IPMNs and the incidence rate ranged from 4.5 to $8 \%$. Thus, IMPNs may be a good predictor for the early detection of PDAC during observation or after the resection of IPMNs. We herein report the rare case of a patient who underwent resection of PDAC that developed in the remnant pancreas 13 years after distal pancreatectomy with splenectomy for IPMNs. PDAC may develop in the remnant pancreas after pancreatectomy for IPMNs; thus, careful long-term follow-up with periodic surveillance, at least every 6 months, is warranted.
\end{abstract}

\section{Introduction}

Intraductal papillary mucinous neoplasms (IPMNs) are characterized by the papillary proliferation of atypical mucinous epithelial cells in the pancreatic ductal system, and the affected pancreatic ducts are often cystically dilated. IPMNs comprise

Correspondence to: Dr Hirofumi Kamachi, Department of Gastroenterological Surgery I, Hokkaido University Graduate School of Medicine, Kita-Ku, Kita 14, Nishi 7, Sapporo, Hokkaido 060-8638, Japan

E-mail: hkamachi@db3.so-net.ne.jp

Key words: intraductal papillary mucinous neoplasms, pancreatic ductal adenocarcinoma, remnant pancreas a spectrum of diseases ranging from adenoma, through in situ carcinoma, to invasive carcinoma (minimally invasive carcinoma and invasive carcinoma derived from IPMNs) (1).

There are two recurrence patterns following resection of IPMNs: Metachronous multifocal occurrence of IPMNs and distinct pancreatic ductal adenocarcinoma (PDAC) in the remnant pancreas. Recent reports have demonstrated that distinct PDAC occurs synchronously or metachronously during the management of IPMNs, with a frequency of $\sim 10 \%$; thus, IPMNs were recently recognized as one of the predictors of PDAC (2-5).

We herein report the rare case of a patient who underwent resection of PDAC that developed in the remnant pancreas 13 years after distal pancreatectomy with splenectomy for IPMNs.

\section{Case report}

A 72-year-old female patient presented to the Department of Gastroenterological Surgery I, Hokkaido University Hospital (Sapporo, Japan) for a routine follow-up examination following distal pancreatectomy with splenectomy $\sim 13$ years prior. Abdominal computed tomography (CT) revealed a $5.5-\mathrm{cm}$ cystic lesion in the tail of the pancreas with a mural nodule, and dilation of the main pancreatic duct (Fig. 1), with another small cystic lesion in the uncus of the pancreas. Histopathologically, IPMN with high-grade dysplasia had been diagnosed after the initial surgery, with negative surgical margins (Fig. 2). Regular medical follow-up visits with imaging examinations were performed every 6 months. At 152 months after the initial operation, CT revealed a $2-\mathrm{cm}$ tumor at the resection margin of the pancreas (Fig. 3). Tumor marker level examination revealed that the carcinoembryonic antigen and Duke pancreatic monoclonal antigen type-2 levels were within the reference limits, whereas carbohydrate antigen 19-9 had increased to $109.7 \mathrm{U} / \mathrm{ml}$ (reference range: $0-36 \mathrm{U} / \mathrm{ml}$ ) and Span-1 has increased to $60.1 \mathrm{U} / \mathrm{ml}$ (reference range: 0-30 U/ml) 
Table I. Laboratory results prior to the second operation.

\begin{tabular}{lc}
\hline Laboratory parameters & Values \\
\hline White blood cells & $6,800 / \mu 1$ \\
Red blood cell count & $408 \times 10^{4} / \mu 1$ \\
Hemoglobin level & $11.3 \mathrm{~g} / \mathrm{dl}$ \\
Hematocrit & $34.5 \%$ \\
Platelet count & $17.0 \times 10^{4} / \mu 1$ \\
HbA1C & $6.1 \%$ \\
Total bilirubin & $0.8 \mathrm{mg} / \mathrm{dl}$ \\
AST & $34 \mathrm{U} / 1$ \\
ALT & $25 \mathrm{U} / 1$ \\
BUN & $15 \mathrm{mg} / \mathrm{dl}$ \\
Creatinine & $0.58 \mathrm{mg} / 1$ \\
Amylase & $54 \mathrm{U} / 1$ \\
CEA & $6.1 \mathrm{ng} / \mathrm{ml}$ \\
CA19-9 & $109.7 \mathrm{U} / \mathrm{ml}$ \\
DUPAN-2 & $143 \mathrm{U} / \mathrm{ml}$ \\
Span-1 & $60.1 \mathrm{U} / \mathrm{ml}$ \\
Elastase 1 & $<80 \mathrm{ng} / \mathrm{dl}$ \\
\hline
\end{tabular}

AST, aspartate transaminase; ALT, alanine transaminase; BUN, blood urea nitrogen; CEA, carcinoembryonic antigen; CA19-9, carbohydrate antigen 19-9; DUPAN-2, Duke pancreatic monoclonal antigen type-2; HbA1C, glycated hemoglobin.

(Table I). The lesion at the resection margin appeared as a hot spot on fluorodeoxyglucose-positron emission tomography (Fig. 4). Remnant proximal partial pancreatectomy and partial gastrectomy were performed due to the patient's age and the presence of comorbidities (diabetes). Histopathological examination of the lesion at the resection margin confirmed a poorly to moderately differentiated adenocarcinoma, which was not derived from the IPMNs (Fig. 5): A metachronous PDAC with vascular and stomach invasion (T3NOM0; R0; stage IIA). The patient received S-1 for 6 months after surgery and remained alive without recurrence at the last follow-up, 17 months after the second operation.

The patient consented to the publication of the case details and associated images.

\section{Discussion}

We herein present the case of a patient who underwent resection of PDAC that developed in the remnant pancreas 13 years after distal pancreatectomy with splenectomy for IPMNs. A cystic lesion was also detected in the uncus of the remnant pancreas, which was diagnosed as IPMN. This patient had been followed up every 6 months after the first operation to detect new lesions in the remnant pancreas. According to consensus guidelines and recent reports on IPMNs, branch duct (BD)-IPMNs are less aggressive compared with main duct (MD)-IPMNs $(6,7)$; therefore, BD-IPMNs that cause no symptoms and have cysts $<30 \mathrm{~mm}$ and no mural nodules, may be followed up with periodic imaging examinations $(1,8)$. Several recent studies investigated the development of
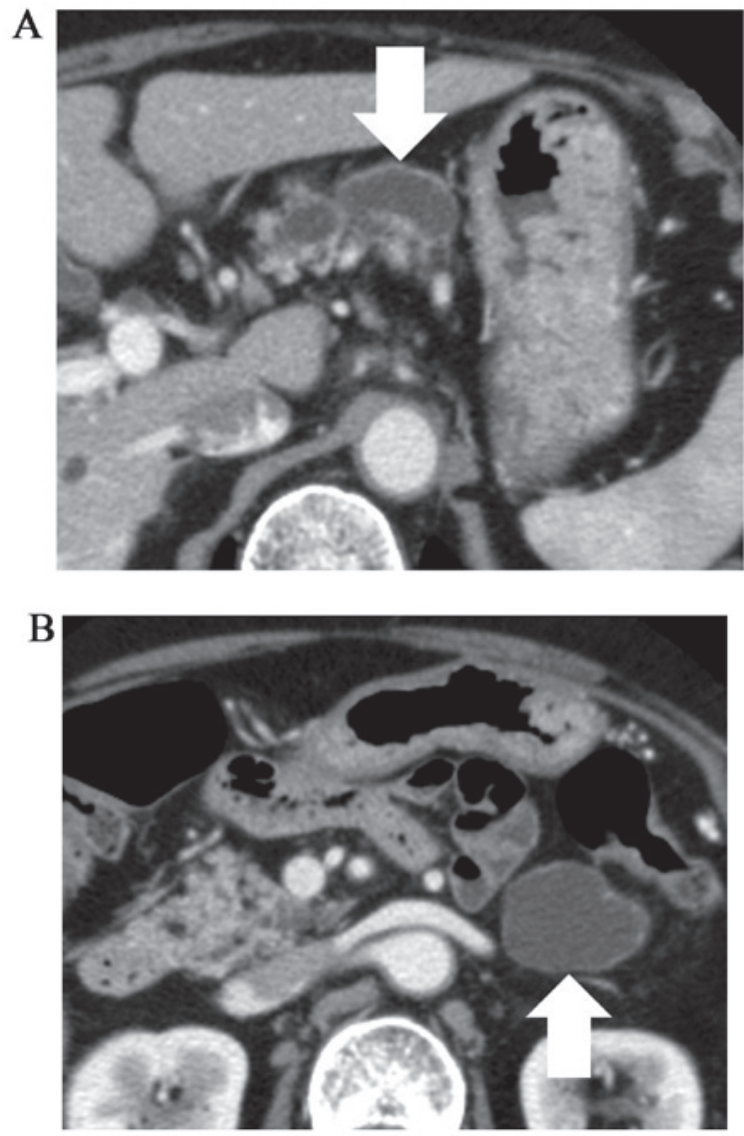

Figure 1. (A) Dilation of the main pancreatic duct was detected (arrow). (B) Computed tomography revealed a cystic lesion in the branch duct in the pancreatic tail (arrow).

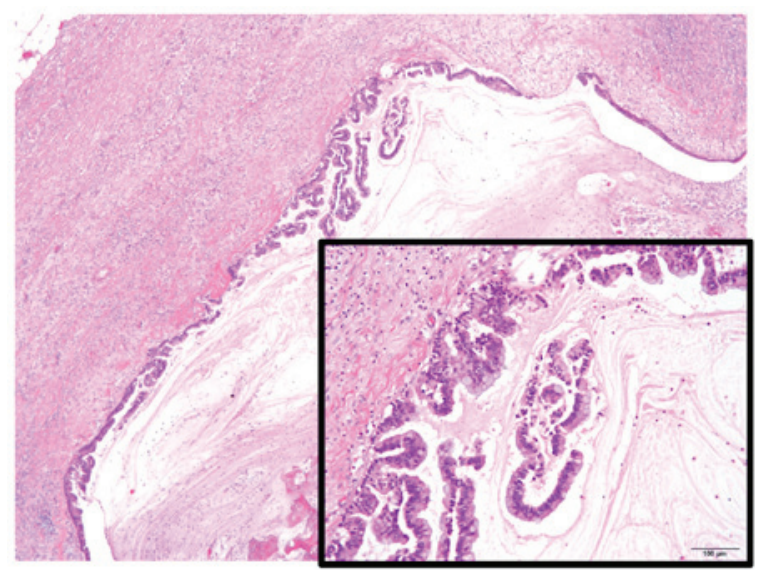

Figure 2. First surgery for intraductal papillary mucinous neoplasm (IPMN) 13 yeas prior. IPMN with high-grade dysplasia was detected in the dilated branches (hematoxylin and eosin staining). The entire mural nodule exhibited moderate dysplasia (magnification, x40). Inset: Mild atypical cells with a slightly swollen nucleus formed a papillary lesion (magnification, x200).

distinct PDAC during follow-up evaluation of BD-IPMNs, and the incidence rate ranged from 4.5 to $8 \%(5,8,9)$. Thus, BD-IMPNs may be a good predictor for the early detection of PDACs during observation of BD-IPMNs or after the resection of IPMNs.

The 2012 international consensus guidelines recommend that, if patients with multifocal BD-IPMNs have known 


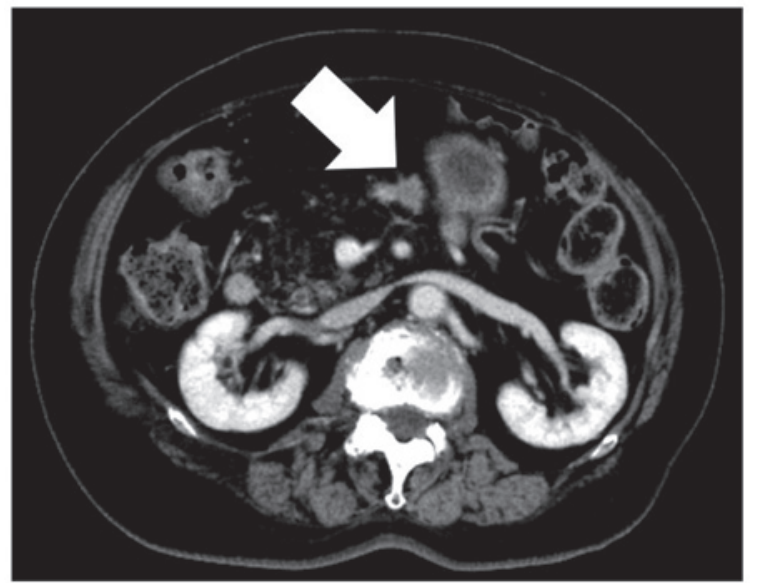

Figure 3. Computed tomography revealed a $2-\mathrm{cm}$ tumor at the resection margin of the pancreas (arrow). The tumor invaded the stomach wall. Most of the pancreatic parenchyma had been replaced by adipose tissue.
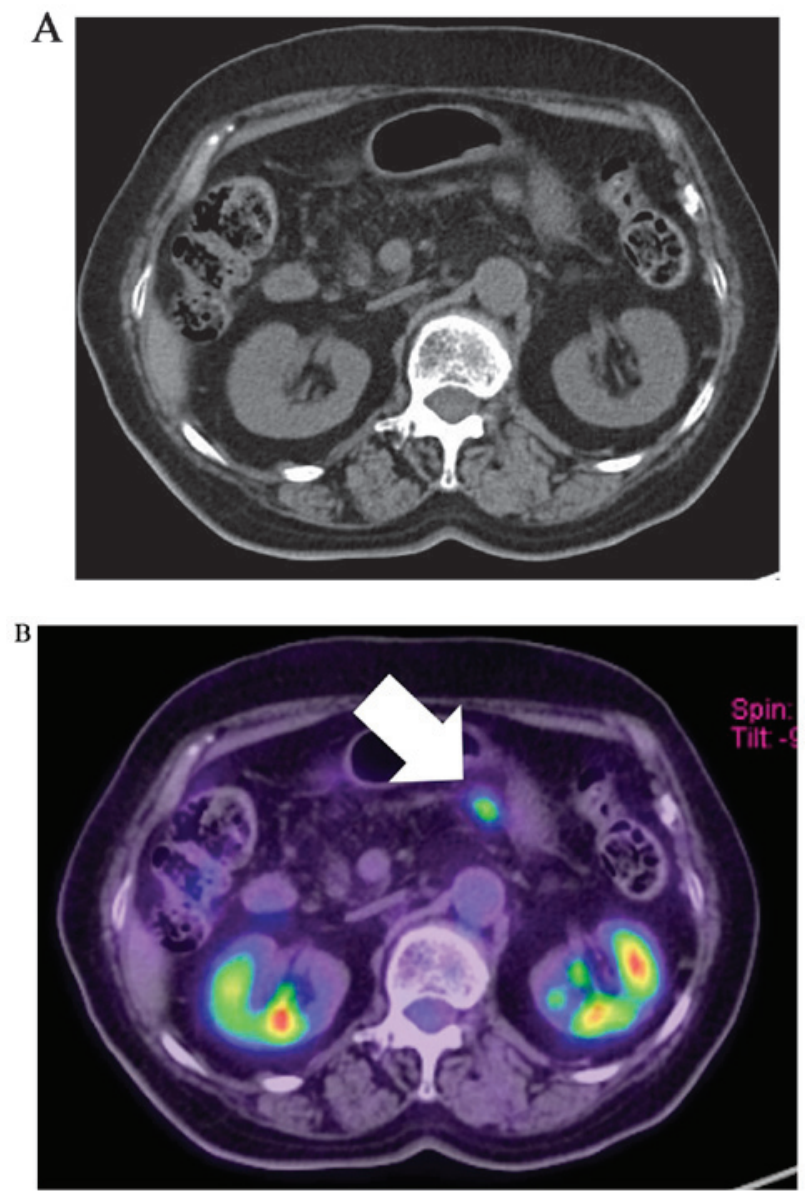

Figure 4. (A) A hot spot on fluorodeoxyglucose-positron emission tomography (arrow) corresponded to (B) the tumor location on computed tomography.

IPMNs in the remnant pancreas following IPMN resection, these patients should be followed up for a short period (3-6 months) by pancreatic magnetic resonance imaging (MRI)/magnetic resonance cholangiopancreatography (MRCP) or CT, to establish stability (1). The patient presented herein was followed up every 6 months due to the relatively high incidence of PDAC. By contrast, Ohtsuka et al
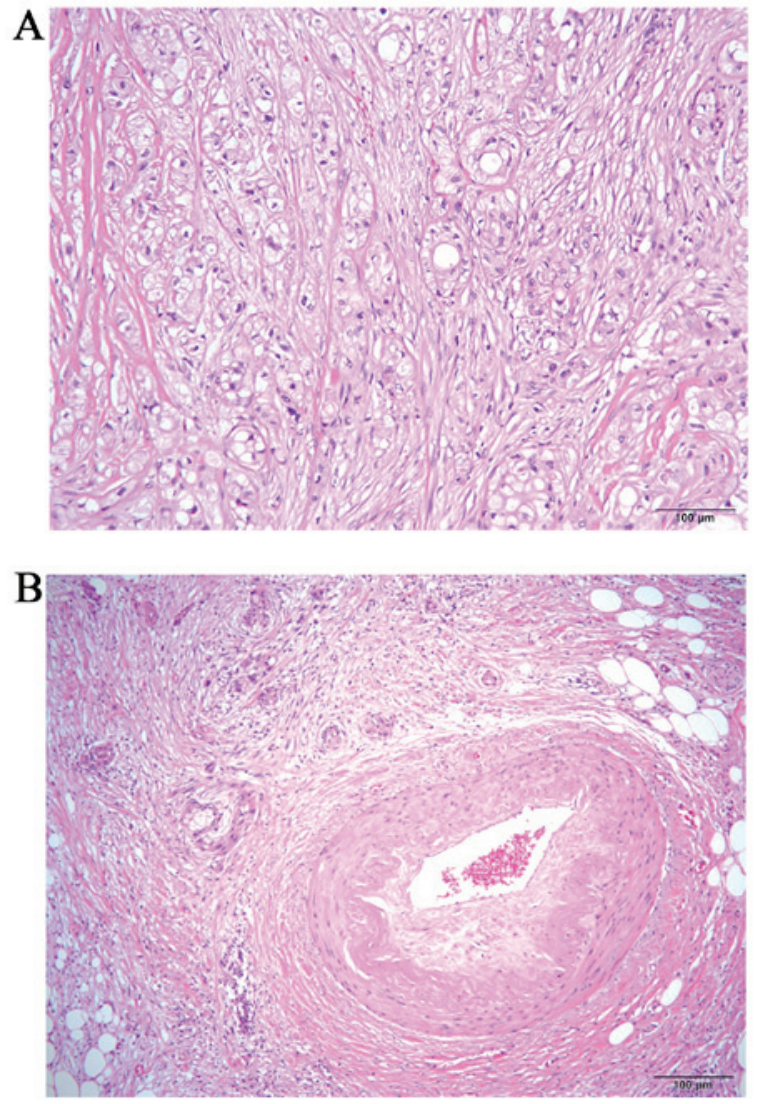

Figure 5. Histopathological examination of the second neoplasm confirmed a poorly to moderately differentiated adenocarcinoma, which was not derived from the intraductal papillary mucinous neoplasm: A metachronous pancreatic ductal adenocarcinoma. (A) Mild atypical cells with slightly swollen nuclei were arranged in irregular ductal structures (magnification, x200) and (B) invaded the parenchyma (magnification, $\mathrm{x} 100$ ).

reported that some metachronous PDACs were unresectable at diagnosis $>10$ years after initial surgery for IPMNs, and performed surveillance every 6 months for the first 2 years after surgery and every 12 months thereafter. They concluded that, based on their experience, annual examination was not sufficient to detect all the cases of resectable PDACs (10). Yogi et al reported that the main pancreatic duct dilates after surgery, and that IPMNs in the remnant pancreas after pancreatectomy for IPMNs were risk factors for recurrence. In that study, half of the patients $(5 / 10)$ who had IPMNs in the remnant pancreas developed recurrence (11). Hirono et al found that remnant pancreatic recurrence may occur $>5$ years after surgical resection, and a second resection may improve survival for patients with IPMNs or PDAC recurrence in its early stages; to improve survival, they proposed continual surveillance of the remnant pancreas every 6 months after the initial operation to detect remnant pancreatic recurrence in its early stages (12). Our patient also presented with an IPMN in the uncus of the pancreas. Based on the abovementioned reports, it is recommended that patients who have IPMNs in the remnant pancreas undergo CT, MRI, or MRCP every 6 months. A follow-up examination schedule for IPMNs should be established, so that PDAC may be detected while it is resectable.

In summary, PDAC may develop in the remnant pancreas following pancreatectomy for IPMNs; therefore, careful 
long-term follow-up with periodic surveillance, at least every 6 months, is warranted.

\section{Competing interests}

The authors declare that they have no competing interests.

\section{References}

1. Tanaka M,Fernández-del Castillo C, Adsay V, Chari S, Falconi M, Jang JY, Kimura W, Levy P, Pitman MB, Schmidt CM, et al: International consensus guidelines 2012 for the management of IPMN and MCN of the pancreas. Pancreatology 12: 183-197, 2012.

2. Yamaguchi K, Kanemitsu S, Hatori T, Maguchi H, Shimizu Y, Tada M, Nakagohri T, Hanada K, Osanai M, Noda Y, et al: Pancreatic ductal adenocarcinoma derived from IPMN and pancreatic ductal adenocarcinoma concomitant with IPMN Pancreas 40: 571-580, 2011.

3. Uehara H, Nakaizumi A, Ishikawa O, Iishi H, Tatsumi K, Takakura R, Ishida T, Takano Y, Tanaka S and Takenaka A: Development of ductal carcinoma of the pancreas during follow-up of branch duct intraductal papillary mucinous neoplasm of the pancreas. Gut 57: 1561-1565, 2008.

4. Ingkakul T, Sadakari Y, Ienaga J, Satoh N, Takahata S and Tanaka M: Predictors of the presence of concomitant invasive ductal carcinoma in intraductal papillary mucinous neoplasm of the pancreas. Ann Surg 251: 70-75, 2010.

5. Tanno S, Nakano Y, Sugiyama Y, Nakamura K, Sasajima J, Koizumi K, Yamazaki M, Nishikawa T, Mizukami Y, Yanagawa $\mathrm{N}$, et al: Incidence of synchronous and metachronous pancreatic carcinoma in 168 patients with branch duct intraductal papillary mucinous neoplasm. Pancreatology 10: 173-178, 2010.

6. Sugiyama M, Izumisato Y, Abe N, Masaki T, Mori T and Atomi Y: Predictive factors for malignancy in intraductal papillary-mucinous tumours of the pancreas. Br J Surg 90: 1244-1249, 2003.
7. Terris B, Ponsot P, Paye F, Hammel P, Sauvanet A, Molas G, Bernades P, Belghiti J, Ruszniewski P and Fléjou JF: Intraductal papillary mucinous tumors of the pancreas confined to secondary ducts show less aggressive pathologic features as compared with those involving the main pancreatic duct. Am J Surg Pathol 24: 1372-1377, 2000.

8. Tanno S, Nakano Y, Nishikawa T, Nakamura K, Sasajima J, Minoguchi M, Mizukami Y, Yanagawa N, Fujii T, Obara $\mathrm{T}$, et al: Natural history of branch duct intraductal papillary-mucinous neoplasms of the pancreas without mural nodules: Long-term follow-up results. Gut 57: 339-343, 2008.

9. Sawai Y, Yamao K, Bhatia V, Chiba T, Mizuno N, Sawaki A Takahashi K, Tajika M, Shimizu Y, Yatabe Y and Yanagisawa A: Development of pancreatic cancers during long-term follow-up of side-branch intraductal papillary mucinous neoplasms. Endoscopy 42: 1077-1084, 2010.

10. Ohtsuka T, Kono H, Tanabe R, Nagayoshi Y, Mori Y, Sadakari Y, Takahata S, Oda Y, Aishima S, Igarashi H, et al: Follow-up study after resection of intraductal papillary mucinous neoplasm of the pancreas; special references to the multifocal lesions and development of ductal carcinoma in the remnant pancreas. Am J Surg 204: 44-48, 2012.

11. Yogi T, Hijioka S, Imaoka H, Mizuno N, Hara K, Tajika M, Tanaka T, Ishihara M, Shimizu Y, Hosoda W, et al: Risk factors for postoperative recurrence of intraductal papillary mucinous neoplasms of the pancreas based on a long-term follow-up study: Proposals for follow-up strategies. J Hepatobiliary Pancreat Sci 22: 757-765, 2015.

12. Hirono S, Kawai M, Okada K, Miyazawa M, Shimizu A, Kitahata Y, Ueno M, Yanagisawa A and Yamaue H: Long-term surveillance is necessary after operative resection for intraductal papillary mucinous neoplasm of the pancreas. Surgery 160: 306-317, 2016.

This work is licensed under a Creative Commons Attribution-NonCommercial-NoDerivatives 4.0 International (CC BY-NC-ND 4.0) License. 